Received: 24/10/2018

\title{
Cognitive Maps of the Beliefs of Pre-service Mathematics Teachers Regarding Mathematics: A Phenomenological Research
}

\section{Vildan Katmer-Bayraklı}

Maltepe University, Department of Mathematics and Science Education, Turkey, vildankatmer@gmail.com

\section{Yavuz Erișen}

Prof., Yildiz Technical University, Department of Educational Sciences, Turkey, erisenyavuz@gmail.com regarding mathematics through plotting their cognitive maps. The PMTs' beliefs regarding the nature of mathematics, and teaching and learning mathematics were considered in depth using a phenomenological approach. Participants in the study were seven PMTs in the fourth year of the Elementary School Mathematics Education Program at a university in Istanbul. Data were collected through individual interviews and analyzed by plotting cognitive maps. The results showed that all PMTs had similar cognitive maps of beliefs regarding mathematics. Although the PMTs stated that they held traditional (teacher centered) beliefs before enrolling in the teacher-training program, they demonstrated that they held more constructivist beliefs as a result of the teacher-training program. The use of cognitive maps was shown to be effective in providing a holistic examination of the beliefs of PMTs and a comparison of their belief systems.

Keywords: beliefs, cognitive maps, pre-service mathematics teachers, phenomenology, qualitative research

\section{INTRODUCTION}

Developments in science and technology have reshaped contemporary education systems and directly influenced the field of mathematics education. Today, the scope of learning mathematics is not limited to merely learning abstract concepts and skills, it also includes the development of a positive attitude toward mathematics along with thinking about mathematics, and an appreciation of mathematics as an important tool in real-life situations (Altun, 2016). Despite the reshaping and restructuring of mathematics education, problems of inadequate mathematics curricula and educational systems, as well as the quality of teachers, appear to constitute persistent pressing issues. The beliefs 
of teachers regarding mathematical knowledge contribute to these problems (Baki, 2014). According to Philipp (2007), teachers play a pivotal role in developing students' beliefs about mathematics. It seems, then, that the beliefs about mathematics of current and pre-service teachers are an important consideration in mathematics education. Therefore, it is worthwhile to identify the beliefs of pre-service mathematics teachers (PMTs) in developing teacher-training programs.

\section{Beliefs Related to Mathematics}

Despite there is no precise definition of the concept of "belief" in current literature, it is, nevertheless, regarded as fundamental to knowledge (Furinghetti \& Pehkonen, 2002; Pajares, 1992; Pehkonen \& Pietilä 2003), attitude (Grigutsch, 1998), and conception (Thompson, 1992). Acccording to Furinghetti and Pehkonen (2002), belief can be defined as subjective knowledge as a component of a judgment formed as a result of experiences and perceptions in one's environment. Grigutsch (1998) recognizes belief as a cognitive dimension of attitude, and Thompson (1992) holds that beliefs are mental structures incorporating individual subconscious conceptions, personal preferences, and viewpoints.

The lack of an agreed-upon definition of belief has led researchers to a number of divergent viewpoints regarding belief in relation to mathematics. Ernest (1989) describes belief regarding mathematics as an individual's conceptions, values, ideology, and tendencies in regard to mathematics, and Raymond (1997) describes belief as a personal value judgment shaped by an individual's experiences with mathematics. According to Schoenfeld (1992), mathematical belief refers to an individual's conceptions and feelings that shape mathematical behaviors. In this study, in line with Ernest's (1989) and Raymond's (1997) definitions, beliefs related to mathematics are approached as the values and tendencies shaped by the individual's past experiences.

\section{The Beliefs of PMTs related to Mathematics}

According to Thompson (1991), the various beliefs of teachers and pre-service teachers combined to form their belief systems. Ernest (1989) organizes the belief systems of teachers and PMTs about mathematics into three subsystems: beliefs about the nature of mathematics (BNMs), beliefs about the teaching of mathematics (BTMs), and beliefs about the learning of mathematics (BLMs). BNMs consider the qualities of mathematics and how mathematics can be used, and BTMs are the beliefs of teachers and PMTs concerning how mathematics should be taught. BLMs are their beliefs about what kind of mathematical learning activities are appropriate for students.

In Pajare's view (1992), equal importance should be attached in educational research studies to examine the beliefs of pre-service teachers as well as those of teachers. In the academic literature, however, little attention is given to the beliefs of pre-service teachers. A review of current literature about beliefs of PMTs regarding mathematics reveals that most studies are quantitative, in which belief scales are used to collect data. In these studies, assessment of beliefs about teaching, learning, and the nature of mathematics is considered (Adnan \& Zakaria 2010; Haser \& Dogan, 2012; Haser, Kayan, \& Işiksal-Bostan, 2013; Steinberg, 1998; Yang \& Leung, 2015) within the 
context of demographic information about the PMTs (Ayvaz \& Dundar, 2014; Çelik et al., 2018; Duatepe-Paksu, 2008; Kayan et al., 2013; Unlu \& Aktas, 2013).

Pajares (1992) holds that "beliefs cannot be directly observed or measured but must be inferred from what people say, intend, and do" (p. 314). Because of the impossibility of directly measuring beliefs, some researchers regard qualitative methods as more appropriate for the study of beliefs (Maasepp \& Bobis, 2015; Munby, 1984; Schunk, 1991). For example, Toluk-Ucar and Demirsoy (2010) studied three PMTs' beliefs regarding mathematics and found that one scored high on the belief scale but revealed opposing beliefs in an interview. The study showed that belief scales alone were not sufficient to examine beliefs and that qualitative data collection should also be employed in the study of beliefs.

An examination of qualitative studies about the beliefs of PMTs regarding mathematics reveals a focus on teaching mathematics. The experiences of PMTs and their coursework in mathematics shape their beliefs on the subject (Boz, 2008; Herron, 2010; Wilkins \& Brand, 2004) and show that PMTs cannot teach lessons in accordance with their beliefs (Boz, 2008; Demirsoy, 2008; Toluk-Ucar \& Demirsoy, 2010).

Due to the abstract and complicated nature of belief, researchers found that plotting cognitive maps of the beliefs of teachers and pre-service teachers was a useful methodology. In such studies, beliefs were approached within the frame of nature of science (Bermejo, Gonzalez \& Mellado, 2004; Coleman, 2014; Irez, 2006; Irez, 2007). Cognitive maps present a holistic image of individuals' beliefs, values, ideology, and the relationships between these elements (Bermejo et al., 2004; Dixon, 2014; Northcott, 1996) and are recognized as an effective tool in studying beliefs (Mellado, 1997; Miles $\&$ Huberman, 1994). There is, however, no research regarding the use of cognitive maps to study beliefs related to mathematics. Therefore, this study proposed to examine cognitive maps of PMTs regarding their beliefs related to mathematics. The beliefs of PMTs, in keeping with Ernest's framework (1989), are categorized as BNMs, BTMs, and BLMs. This study attempts to answer the following research questions:

1. What are the beliefs of PMTs regarding the nature of mathematics?

2. What are the beliefs of PMTs regarding the teaching of mathematics?

3. What are the beliefs of PMTs regarding the learning of mathematics?

\section{METHOD}

\section{Research Design}

This study is a qualitative research using an interpretative paradigm that allows observation of a phenomenon from the perspective of the participant (Merriam, 2009). In this study, the beliefs of PMTs regarding mathematics are viewed as an individual's values shaped by experiences with mathematics (Raymond, 1997). A phenomenological design was used to interpret individuals' experiences concerning a concept or phenomenon (Creswell, 2013). 


\section{Participants}

Participants in this study were selected from fourth-year PMTs enrolled in the Elementary School Mathematics Teaching Program at a university in Istanbul, from which the researchers received permission to conduct the study. To select participants for the study (Glesne, 2011), 20 PMTs who volunteered for the study attended focusgroup interviews of approximately one hour in two sections of 10 PMTs each. Through the use of open-ended questions, researchers generally observed the PMTs' beliefs related to mathematics. Videos of these interviews were recorded with the permission of the PMTs. Using focus-group interviews, the technique of purposeful sampling, which provides an opportunity to thoroughly investigate an issue by choosing situations that are rich in terms of knowledge (Patton, 2002), was used to select participants. The study group selected seven PMTs, five female and two male volunteers, with a view to ensure maximum variation (Glesne, 2011) in the participants' mathematics experience. Participants ranged from 21 to 25 years of age $(\mathrm{M}=23)$, and are represented in the study as P1, P2, P3, P4, P5, P6, and P7.

All participants had completed most of the required mathematics education courses, and they also were enrolled in the School Experience course based on an elementary school internship. All had previous experience teaching mathematics as private tutors and/or as interns at private schools.

Participants were assigned one of three groups based on their reason for enrollment in the teacher-training program. Participants P1, P2, and P7 were enrolled by personal choice, and P3 was enrolled at the request of her family. P4, P5, and P6 studied in other departments at other universities before enrolling in the Mathematics Teacher Training Program.

\section{Data Collection Tools}

For this study, two face-to-face individual interviews were conducted with each participant. In the first interview, a semi-structured interview form elicited the beliefs of the PMTs regarding mathematics. According to Colaizzi (1978), the success of phenomenological studies depends on focusing questions on "lived experiences." In this regard, while creating the interview form, the experiences of the participants with regard to this phenomenon was also considered, and made use of academic literature on this topic (Raymond, 1997; Spangler, 1992; Toluk-Ucar \& Demirsoy, 2010).

The interview form consisted of 17 open-ended questions about the nature of mathematics (7 questions), the teaching of mathematics (5 questions), and the learning of mathematics (5 questions). Four senior researchers in mathematics education contributed throughout to formulate and adapt the questions in current literature to this study. Later, a second face-to-face interview was conducted with each participant concerning the cognitive map that resulted from the data analysis of the initial interview.

\section{Data Collection}

Before the interviews, PMTs were assured their identities would not be revealed. PMTs were also informed that they could withdraw from the study at any time; however, none 
of the participants withdrew. Interviews were conducted by one of the researchers and tape recorded with the permission of the PMTs. Interviews began with small talk about current issues and events, followed by a brief discussion about the aim of this study. Then answers to the interview form questions were solicited from the PMTs. Each interview lasted approximately 50 to 60 minutes.

Four weeks after the first interviews, second interviews of approximately 15 minutes were conducted. In these interviews, the PMTs were shown their individual cognitive maps to confirm the results with the participants to provide confirmability of the study (Guba \& Lincoln, 1994).

All interviews were conducted in consultation rooms or classrooms at the university. All data obtained were securely stored.

\section{Data Analysis Procedure}

A four-stage data analysis procedure suggested by Hewson and Hewson (1989), and generalized to plotting cognitive maps by Irez (2006), was used. In the first stage, each interview was transcribed and the data were coded by assigning a number to each question on the interview form asked by the researcher. The PMTs' responses with regard to the units of information were also numbered. An example of coding is given below:

Researcher (Question 1): With regard to your own experiences, what does mathematics represent in your opinion? How would you describe it?

P1: 1. I read a study entitled mathematics is the language of nature. Personally, I believe this is true. 2. I believe numbers have a place in our life 3. To say "Mathematics is life" would be an exaggeration, but... 4. I could say that mathematics is the language of nature.

In the second stage, theme and subtheme headings about the nature of mathematics, its teaching, and its learning were formulated according to content analysis of the interview transcripts.

In the third stage of data analysis, participants' detailed answers concerning a particular theme were summarized into one statement. In Figure 1, some statements derived from analysis of P1's interview transcript are shown with codes.

Mathematics is the language of nature $(1.1,4)$

Mathematics is a science (2.1)

Mathematical information can change $(5.1,2)$

For example, number zero (6.1)

Figure 1

An example of summarized statements and codes 
In Figure 1, "5.1,2" indicates that the answer to the fifth interview question matches information unit found in sentences 1 and 2 .

In the fourth and final stage, cognitive maps of the PMTs were plotted using the themes, subthemes, and statements from the second and third stages. Statements such as those in Figure 1 were analyzed carefully, divided into categories, and the relationships between those categories were defined.

Figure 2 is an example of a part of the cognitive map of P1's beliefs regarding mathematics.

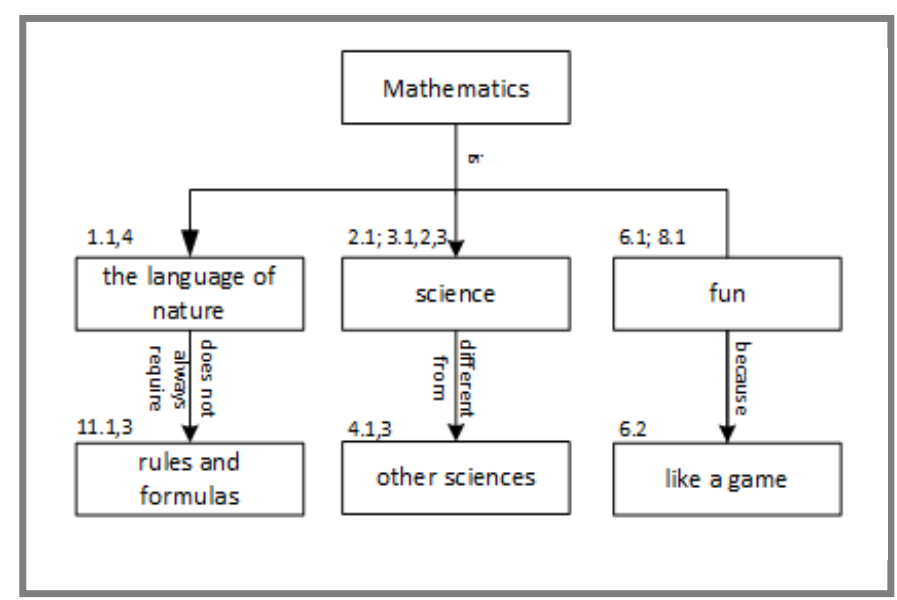

Figure 2

Plotting of P1's cognitive map.

The codes at the top of each box on the cognitive map indicate the section of the interview from which they were derived.

At each stage of data analysis, opinions were solicited from two experts in qualitative research methodology and three experts in mathematics education in order to confirm credibility of the study.

\section{FINDINGS}

In Table 1, a summary of findings of the beliefs of PMTs identifies the similarities and differences in beliefs. The left column of the table comprises themes, subthemes, and statements from the second stage of data analysis. Individual PMT beliefs are indicated by the bullet $(\bullet)$ symbol in a particular theme. 
Table 1

Pre-service Mathematics Teachers' Beliefs Related to the Nature of Mathematics, Its Teaching, and Learning.

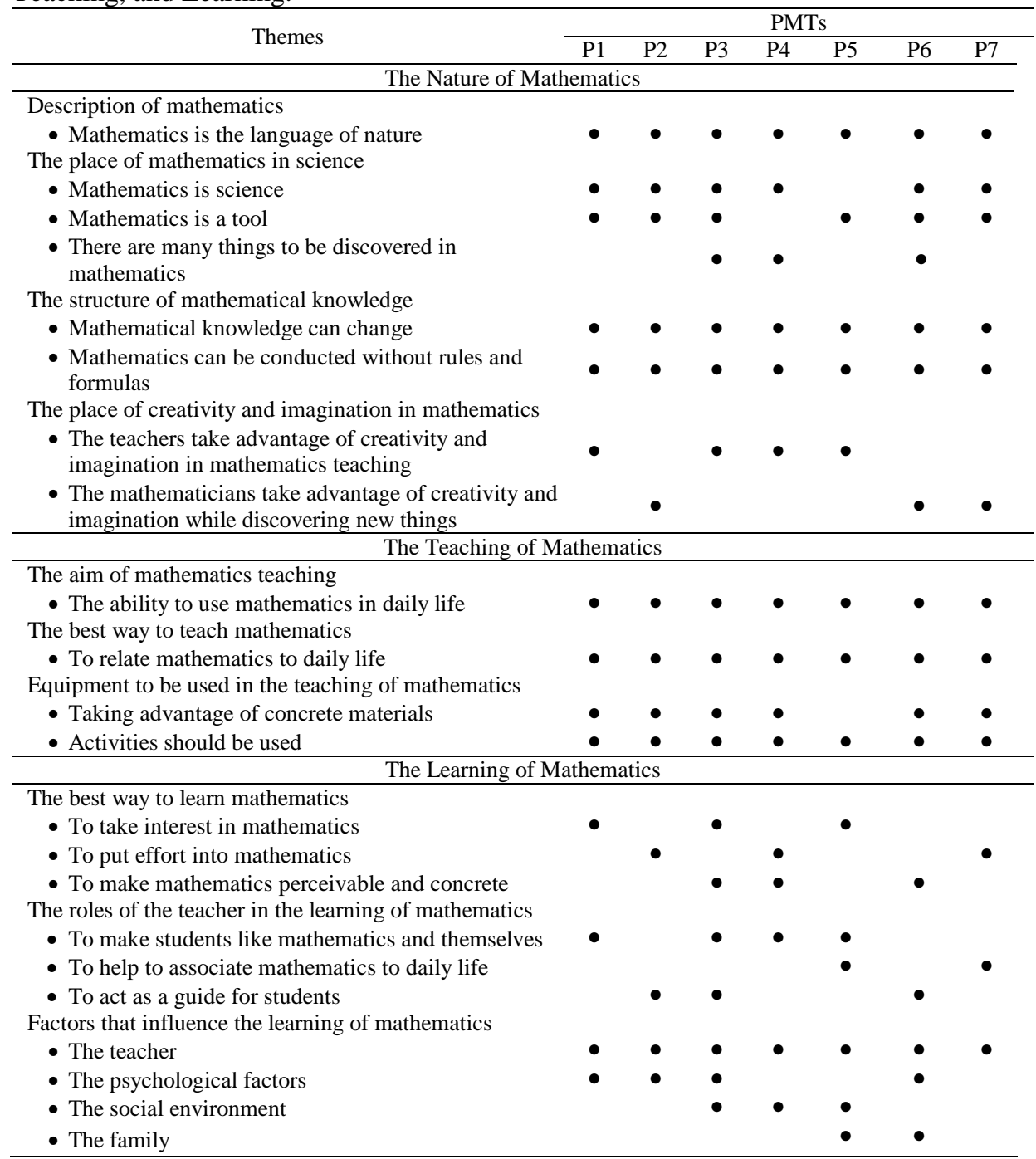

A cognitive map was plotted for each PMT using the indicated themes, subthemes, and statements shown in Table 1. Despite their different backgrounds and experiences, the PMTs were seen to hold almost similar beliefs. The cognitive map of a PMT from each participant group is given below. For example, the cognitive map of P2, one of the three participants enrolled in the teacher-training program by personal choice, is shown in Figure 3: 


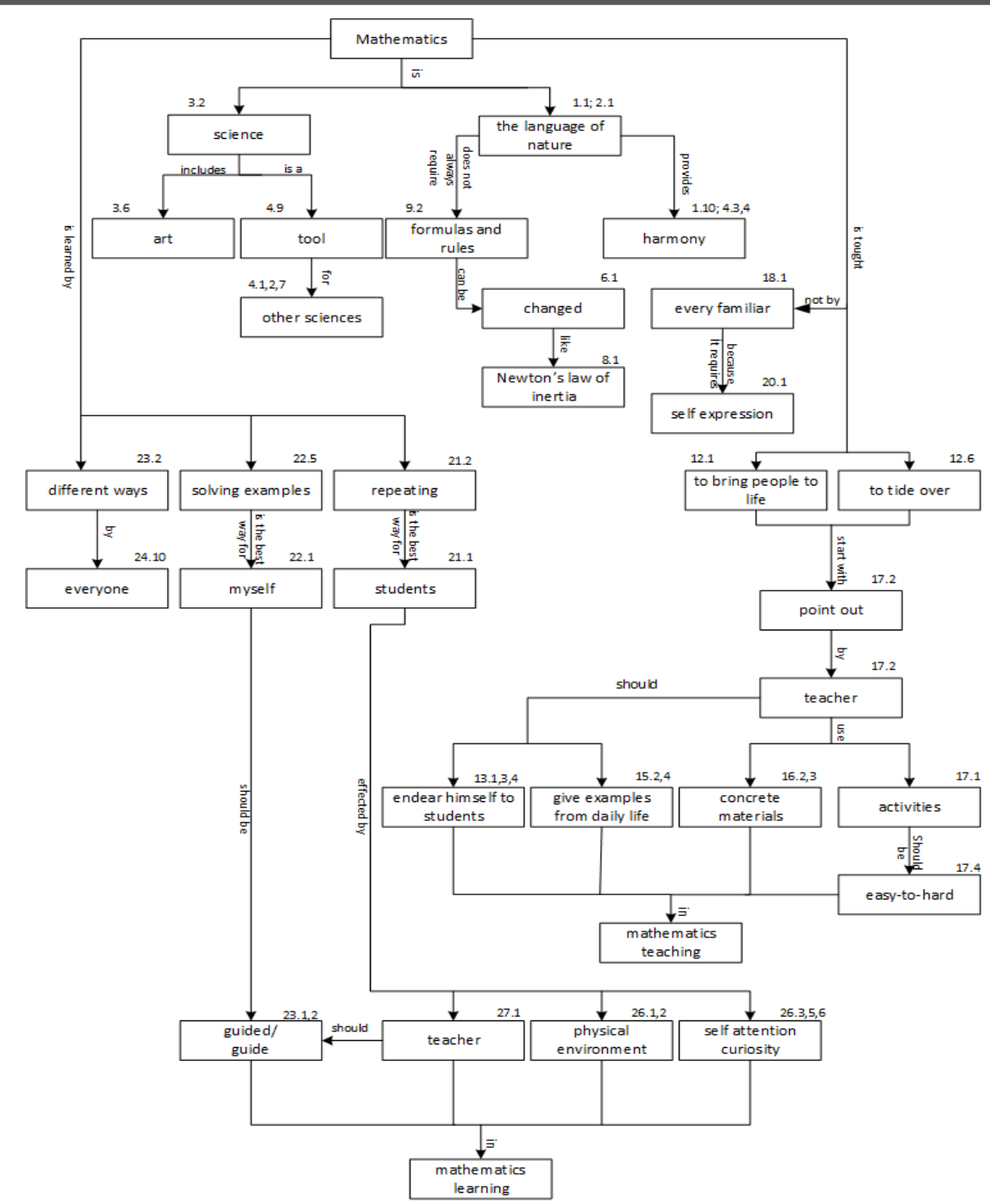

Figure 3

P2's cognitive map

The cognitive map of P4, one of three PMTs who joined the Mathematics Teaching Program after studying elsewhere in a different department, is shown in Figure 4. 


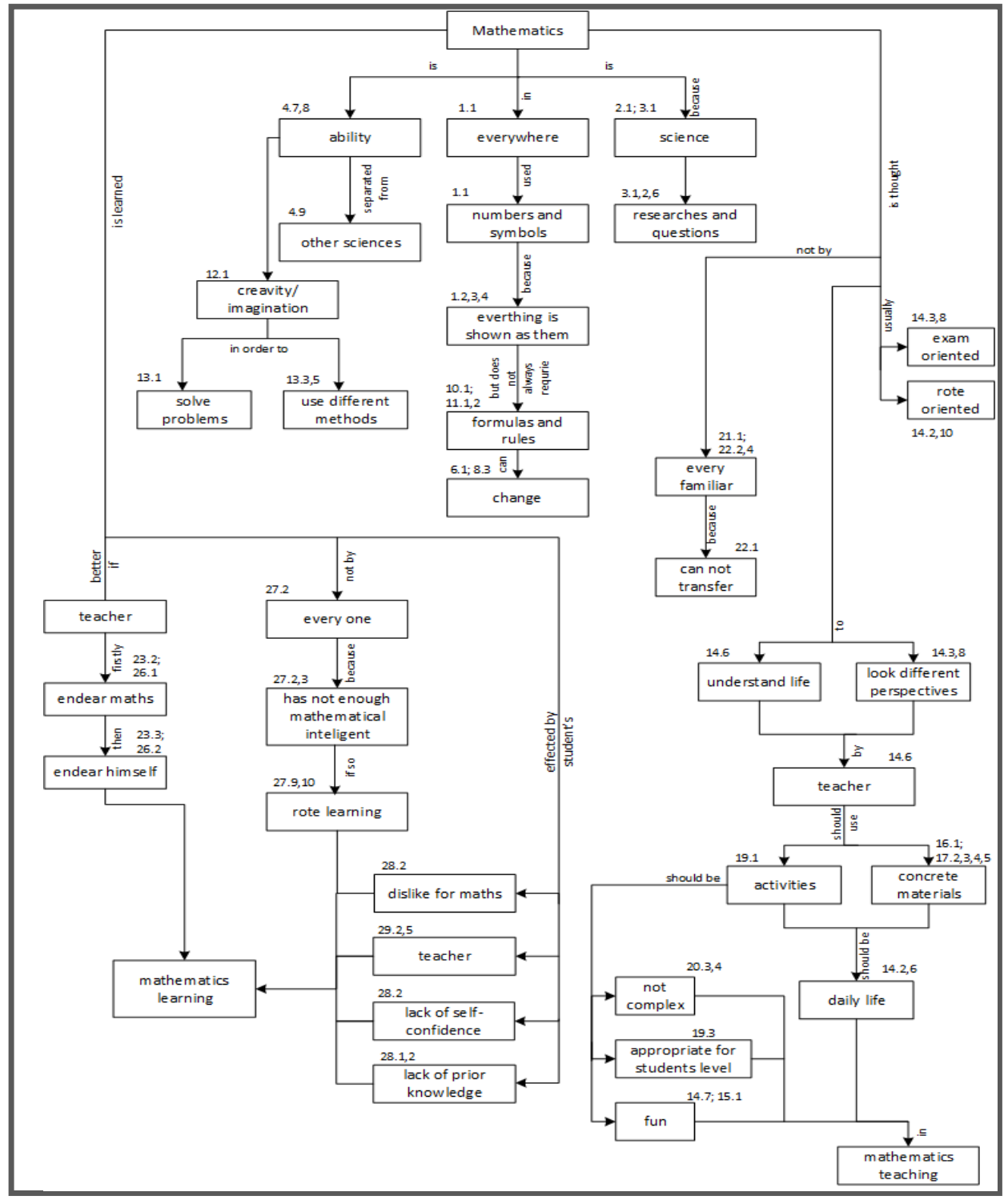

Figure 4

P4's cognitive map

The cognitive map of P3, who joined the Mathematics Teaching Program by parent request, is shown in Figure 5. 


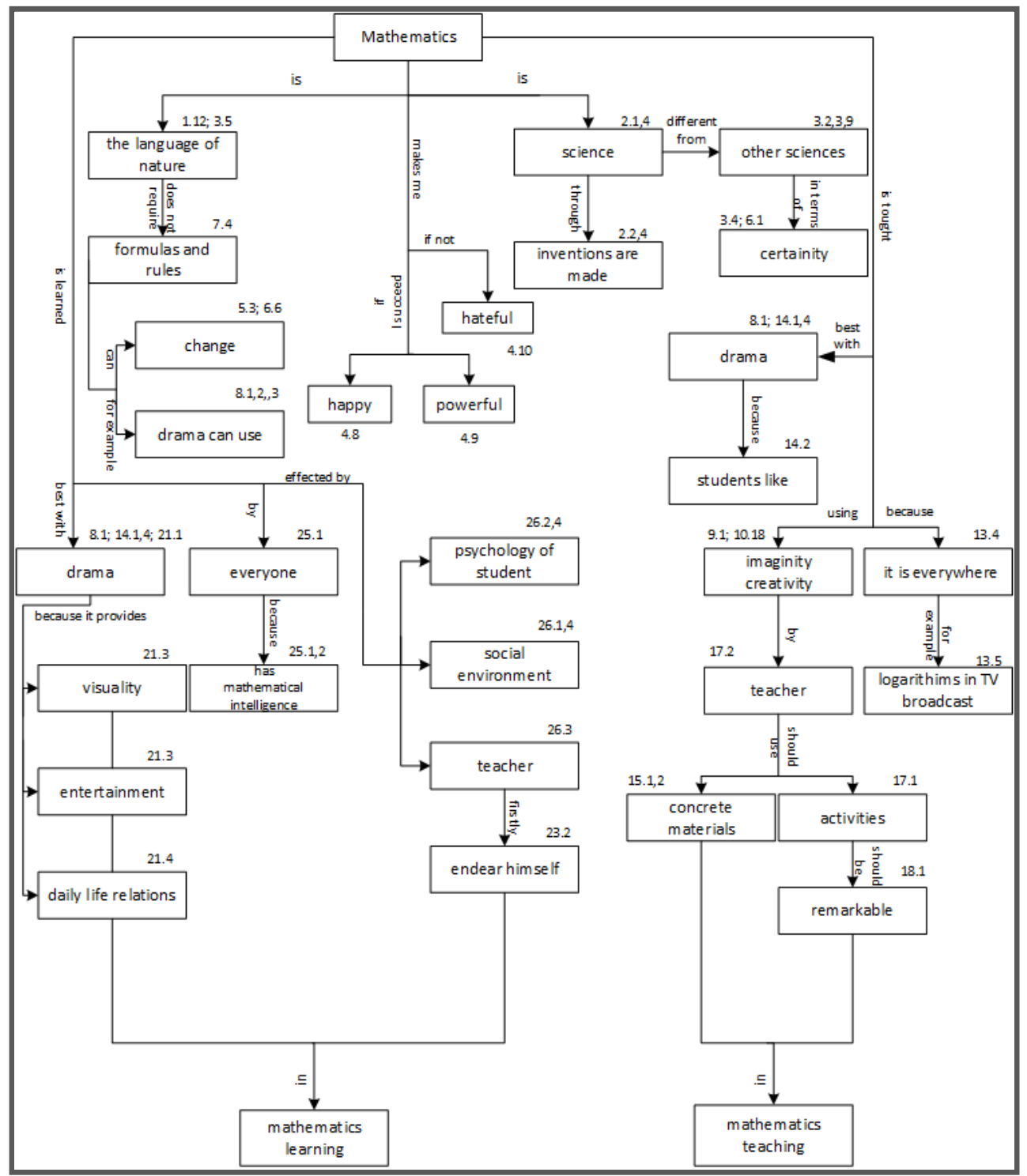

Figure 5

P3's cognitive map

As shown in Figures 3, 4, and 5, most of the beliefs of PMTs are parallel to each other and likewise some differences can be identified. The similarities and differences 
between the beliefs of PMTs related to the nature of mathematics, teaching mathematics, and learning mathematics are indicated by the themes, subthemes, and statements.

\section{Beliefs Related to the Nature of Mathematics}

The beliefs of PMTs relating to the nature of mathematics can be grouped under four main themes: the description of mathematics, the place of mathematics in science, the structure of mathematical knowledge, and the place of creativity and imagination in mathematics.

\section{Theme one: The description of mathematics}

All PMTs described mathematics as the "language of nature." For example, P7 described mathematics as, "It is applied to nature rather than a series of numbers or symbols....I could say it is the language of nature." P6 similarly described mathematics: "It exists in everything because we are people who symbolize everything as we live." P4 explained the same situation in a different way:

Mathematics is a fact present inside everything. When we listen to music, a certain ratio of notes emerges. Mathematics is a phenomenon that is present throughout all of nature and our whole lives, and sometimes we are not even aware of it.

As seen from the above comments, although each PMT described mathematics in a different way, all held that mathematics is everywhere and in everything in nature.

Theme two: The place of mathematics in science

The majority of the PMTs view mathematics as a science. They provide reasons such as "mathematics is a tool for various branches of science" and "has an exploratory aspect." For example, P7 cited "mathematics as being one of the most important branches of science since it has a great role in the development of other disciplines." P6 summarized her view that "there are still numerous aspects of the subject to be discovered, and since this discovery process still continues, it is, in my opinion, a science." P5, however, considered the topic from a different perspective:

It is not a science in my opinion, even if it is accepted as a branch of science. Because I do not think that everything involving discovery can be described as a science. Mathematics is in fact related to all branches of science that use it.

Although this participant considered mathematics a tool for other branches of science and thought that there were aspects yet to be discovered and thus expressing beliefs similar to other PMTs, he did not believe that it could be considered science.

\section{Theme three: The structure of mathematical knowledge}

This theme was categorized under two subthemes: the changeability of mathematical knowledge and rules and formulas in mathematics.

The changeability of mathematical knowledge. All PMTs thought that mathematical knowledge, rules, and formulas could change. Mathematics at a basic level appeared certain and clear to them, but knowledge appeared more changeable in advanced 
mathematics. As P6 explained: "The basic mathematical multiplication tables have not changed for many years. However, if something new gets discovered at an advanced level such as integral calculus, then some of the things we have learned may actually change." P1 expanded on this: "The number zero. Until eighth class we accepted zero as belonging to a set of natural numbers, however at university our lecturers do not accept zero as a natural number."

Although most PMTs were not able to provide examples of change in mathematical knowledge, they believe that mathematical knowledge is dynamic and is neither certain nor clear.

Rules and formulas in mathematics. All PMTs held that mathematics could be applied without rules or formulas. For example, P5 explained: "The rules and formulas did not exist in the past. Indeed, they only emerged at the end of studies in order to express our opinions in a more concrete way and realize those expressions easier." Similarly, P3 expressed that "rules and formulas merely simplify the work because there was still mathematics before they existed."

As revealed in their comments, the PMTs thought that rules and formulas merely helped simplify subjects and make them tangible.

Theme four: The place of creativity and imagination in mathematics

All PMTs thought that creativity and imagination were important in mathematics. For example, P5 believed that a teacher should use creativity and imagination in class:

Mathematics does not immediately take root in the minds of students. The examples and questions used in the lesson need to be powerful. So, the teacher should have a good imagination in order to prepare the lesson to be more effective.

Similarly, P7 expressed: "If one does not make use of creativity or imagination, I do not think that a mathematics lesson can truly take place." P2, who believed creativity and imagination is involved in discovery, explained her views with an example from physics: "As you know, the apple fell on Newton's head. Then he discovered the law of gravity. Every Tom, Dick, and Harry sees that apple fall. However, only Newton could picture the fall of apple and he discovered gravity."

As can be seen from the above comments, some PMTs, in mentioning creativity and imagination, approached mathematics from the viewpoint of a teacher, and others approached mathematics from the viewpoint of a mathematician.

\section{Beliefs Related to the Teaching of Mathematics}

The beliefs of PMTs regarding teaching mathematics were categorized under three themes: the aims of teaching mathematics, the best ways to teach mathematics, and equipment needed in teaching mathematics. 


\section{Theme one: The aims of teaching mathematics}

All PMTs criticized that teaching mathematics usually focused on examinations and that mathematics was presented to students as formulas and rules. Moreover, most PMTs felt mathematics was taught without providing reasons for studying mathematics, and it was removed from daily life. For example, P7 expressed: "This is the formula. When you see something similar, just apply the formula. Without knowing where it comes from. This is how we have been taught for years." For this reason, most PMTs believed that ideally mathematics education should aim to help students acquire an understanding of life based on the idea that mathematics is present everywhere. They oppose rote learning. P4 summarized these views of the PMTs:

In mathematics lessons, we always received rules and formulas. Mathematics is always taught for examination purposes. But when you get into real mathematics, it is completely different. Indeed, we can use mathematics to look at life and to find solutions to life.

P7 believed that the aim of teaching mathematics was to "prepare people for life to a certain degree and after having reached that, to increase general mental capabilities by carrying out interpretations of mathematics."

\section{Theme two: The best way to teach mathematics}

All PMTs believed that the best way to teach mathematics is by relating it to daily life and providing reasons for its study. For example, P1stated: "To teach something with its reasons is always better. It is more appropriate to explain reasons with regard to the topic and to explain this together with where we will use it in real life." P3 believed that the best way of integrating mathematics into daily life was through the use of drama: "As mathematics is not a subject particularly enjoyed by students, lessons can be made more enjoyable using drama in mathematics teaching." P5 suggested using the history of mathematics in teaching:

Lessons should be presented with some segments from the history of mathematics. Who found this? Why did they do it? In what area of their life was it useful? Such things provoke the curiosity of students. The knowledge learned becomes permanent.

Thus, according to the PMTs, the successful result of effective teaching is the ability of students to use mathematics in daily life.

Theme Three: Equipment Needed in Teaching Mathematics

The PMTs stressed the abstract nature of mathematics teaching definitely needed concrete materials. The most ardent supporter of this view, P6, stated:

Certainly the best way to teach mathematics is the use of concrete materials. I think that the students will learn easier when concepts are brought to life by the use of concrete materials, and that it [knowledge] will remain for a longer time in their minds. 
P5, however, objected to using tangible materials. This participant, who had observed such teaching, commented:

I do not support material development. I saw how the teacher brought cubes to a lesson about exponential numbers. The students did not even know what exponential numbers were. And when you bring materials to class in such a case, the children don't understand the concept. There was no meaning to the demonstration of piling material things up on one another, and I think it was a waste of time.

All other PMTs believed that materials facilitate permanent learning, and materials designed to teach mathematics awaken the interest and curiosity of students.

All PMTs thought that interesting activities designed to promote the curiosity of students were necessary in teaching mathematics. In particular, PMTs thought that such activities could facilitate participation by all students in the lesson and make mathematics lessons more enjoyable. For example, P1 stated:

Activities are fun and draw the attention of the students and they can be conducted together with the class. I'd look for an activity that would ensure high levels of participation, and I would try to derive the maximum degree of efficiency from the activity.

Two PMTs stressed using activities appropriate to the class level. P5 supported this view in the preparation of activities: "I have to look at the level of the class. Who are the students? How much do they know? What is their background in the topic up to now?"

\section{Beliefs Related to the Learning of Mathematics}

Beliefs of PMTs regarding the learning of mathematics were categorized under three theme headings: the best way to learn mathematics, the role of the teacher in the learning of mathematics, and factors that influence the learning of mathematics.

Theme one: The best way to learn mathematics

Three PMTs believed that optimal mathematics learning required an interest in mathematics, and they often mentioned this in the interviews. For example, P5 felt that "almost everybody who enjoys and is interested in mathematics could learn it." PMTs who concurred held that quality learning required raising students' interest in mathematics.

Three PMTs associated optimal mathematics learning with attaching more importance to practice than theory in learning mathematics. They believed that the best way to learn mathematics was "to think about it and to put effort into it." For example, P7 stated, "Mathematics needs effort. I think it is necessary to pick up a pen or pencil and try hard. Mathematics doesn't mean just memorizing. Some things have to be made clear and require a lot of effort."

In concluding, P6 believed the best way to learn mathematics was through concrete or tangible lessons: "It has been proven that $80 \%$ of what we see remains in our minds. If a 
topic can be concretized, it is necessary to make the topic accessible and concrete so the students can absorb and internalize it."

Theme two: The role of the teacher in learning mathematic

All PMTs emphasized the importance of teachers in learning mathematics. Some PMTs believed their role was to make mathematics and themselves likable to students. For example, P5 stated that the teacher's role was:

...to endear mathematics and ourselves. First ourselves, then mathematics. If a student likes you, and does not want to upset you, he will pay attention to the lesson. After a certain point, she will notice that mathematics is enjoyable and will begin at that moment to learn as he gradually believes in his ability to do it.

P5 and P7, who emphasized that teachers demonstrate the use of mathematics in everyday life, considered their main role in facilitating learning was to relate subjects to real life. P7, informed by classroom observation, commented, "On that day, there was a question about rice. The teacher asked if anyone would like to cook pilaf. I think that mathematics has to be linked to our lives and such a teaching approach is necessary."

Two PMTs described themselves as guides rather than as teachers who transfer knowledge to students. P6 stated that to teach mathematics is "to draw a beautiful and smooth road without obstacles between the student and knowledge; to be a guide who ensures easy access to knowledge."

Theme three: Factors that affect the learning of mathematics

All PMTs saw the teacher as the most important factor influencing the learning of mathematics. They felt the teacher facilitates successful learning by being well liked by students, by making mathematics enjoyable, and by clearly conveying information about the subject matter to learners. For example, P1 explained, "In my opinion, what a teacher can convey, how he/she conveys it, and whether he/she is liked by the students is very important." All PMTs, however, believed other factors contributed to learning mathematics.

Four PMTs thought that the psychological status of students influenced learning mathematics, including their desire to learn, and that problems in their personal life affect learning. P3 expressed that "the psychological condition of a student, whether or not there exists any underlying problem, may affect the learning of mathematics." P1 stressed that "the psychological state of the student is of course vitally important."

Three PMTs thought the social environment could affect learning mathematics. For example, P4 explained, "the student's circle of friends may affect learning mathematics, because the students may be influenced by them in either a positive or negative fashion." In addition, according to two PMTs, the student's family affects learning mathematics to a great extent. P6 emphasized this point: "If the family displays a domineering attitude, then the student's failure in mathematics is inevitable."

In summary, the PMTs were insistent that the best way to teach and to learn mathematics was to associate topics with events and examples from daily life, and 
various factors influence student learning. A teacher should first of all guide students in learning mathematics.

\section{DISCUSSION AND CONCLUSION}

This study aims to examine cognitive maps of PMTs regarding their beliefs related to mathematics expressed by three overarching research questions. In the first research question, the BNMs of PMTs were examined. The results demonstrated that the PMTs, rather than seeing mathematics as a collection of unchanging rules and formulas (Duatepe-Paksu, 2008; Steinberg, 1998), believed that mathematics existed everywhere in nature and constituted a dynamic discipline with many aspects yet to be discovered. These findings corresponded with results of prior studies (Isiksal et al., 2007; Kayan et al., 2013; Yang \& Leung, 2015). Furthermore, according to the majority of PMTs, mathematics is a branch of science which uses creativity and imagination considerably and contributed to the development of other scientific disciplines.

The second research question of this study analyzed the PMTs' BTMs. According to the findings, the PMTs believed that effective teaching of mathematics required tangible materials and activities that linked topics with real life in order to minimize rote learning.

In the third question, the PMTs' BLMs were identified. The teacher was considered an essential factor influencing the learning of mathematics. PMTs believed that effective mathematics learning was best accomplished with an accessible teacher who made mathematics enjoyable for the students and linked the subject to daily life. An interesting finding was one PMT's suggestion that the history of mathematics be included in mathematics lessons. In the new elementary and high-school mathematics curriculum in Turkey and current studies, including the history of mathematics is suggested to help students develop a positive attitude toward mathematics and provide an opportunity to comprehend the discipline better (Karakus, 2009; MNE, 2013a; MNE, 2013b; Tillema, 2005)

In the present study, there are similarities between the BTMs, BLMs, and BNMs of PMTs. As Ernest (1989) points out, BNMs are an indicator of BTMs and BLMs. Results demonstrated that the BTMs and BNMs of PMTs were generally in keeping with the philosophy of the elementary school mathematics curriculum in Turkey (MNE, 2013a). Adoption of a constructivist approach since 2005 in mathematics curricula in Turkey is reflected in teacher-training programs. In their studies, Wilkins and Brand (2004) indicated that courses about learning and teaching mathematics for PMTs had been effective in changing the traditional (teacher centered) views of PMTs. In this study, the beliefs of PMTs that were compatible with the mathematics curriculum are thought to be derived from the PMTs teacher-training program.

In this study, PMTs holding traditional views prior to enrolling in the teacher-training program demonstrated more constructivist BNMs, BTMs, and BNMs after their training. Similar results are observed in other studies regarding this topic (Dede \& Karakus, 2014; Demirsoy, 2008). The PMTs had varied experiences and a range of beliefs and expectations regarding mathematics before enrolling in the teacher-training 
program. In this study, the beliefs of PMTs were found to be similar based on their cognitive maps. Although Raymond (1997) and White (2000) hold that teacher-training programs have a minimal effect on the beliefs of PMTs, all PMTs in this study stated that their beliefs relating to mathematics were positively and dramatically influenced by the teacher-training program. These results are supported by results in other research (Dede \& Karakus, 2014; Haser, 2006; Wilkins \& Brand, 2004).

It was seen, however, that although PMTs developed a constructivist understanding of mathematics education, traces of their traditional beliefs can be identified due to their early mathematics education (Ball, 1990; Raymond, 1997).

The use of cognitive maps in this study allows a holistic examination of the beliefs of PMTs as well as the easy identification of similarities and contradictions in those belief systems. The results in the academic literature also show that the use of cognitive maps is an effective analytical procedure to reveal the beliefs of PMTs (Bermejo, et al. 2004; Coleman, 2014; Dixon, 2014).

\section{SUGGESTION}

The examination of the beliefs of pre-service teachers is an important subject with regard to the effectiveness and development of teacher-training programs. In this context, a number of suggestions can be presented for mathematics teacher-training institutions. These institutions should identify the beliefs of PMTs regarding mathematics who begin their training programs and prepare their learning environments in such a way that they can bring about a positive change in their belief systems.

In the light of the obtained results, some suggestions can be made for future researches. In this study, plotting of cognitive maps of PMTs provided an opportunity to present a holistic picture of the PMTs' beliefs. In future, studies can be conducted including beliefs of in-service teachers regarding mathematics using cognitive maps.

In this study, it is seen that teacher training program plays a great role in the development of the beliefs related to mathematics of PMTs. It is thought that the beliefs of instructors of teacher-training programs may also influence PMTs' beliefs. In this context, examination of the beliefs of instructors can be a new research topic. 


\section{REFERENCES}

Adnan, M., \& Zakaria, E. (2010). Exploring Beliefs of Pre-Service Mathematics Teachers: A Malaysian Perspective. Asian Social Science, 6(10), 152-159. http://doi.org/10.5539/ass.v6n10p152

Altun, M. (2016). Liselerde matematik ogretimi [Teaching mathematics in high schools]. Bursa: Alfa.

Ayvaz, U., \& Dundar, S. (2014). What are the Beliefs of Primary and Primary Mathematics Teacher Candidates about Mathematics? International Journal of Educational Researchers, 5(2), 1-15.

Babylonian Square Root Method]. Necatibey Faculty of Education Electronic Journal of Science and Mathematics Education, 3(1), 195-206.

Baki, A. (2014). Kuramdan uygulamaya matematik egitimi [Mathematics education from theory into practice]. Ankara: Harf.

Ball, D. L. (1990). The Mathematical Understandings that Pre-Service Teachers Bring to Teacher Education. The Elementary School Journal, 90(4), 449-466.

Bermejo, M. L., Gonzalez, T,. \& Mellado, V. (2004, September). Cognitive maps from interviews as a procedure to analyze science teachers' conceptions of the nature of science. Poster session presented at the Proceeding of the First International Conference on Concept Mapping, Pamplona, Spain.

Boz, N. (2008). Turkish Pre-Service Mathematics Teachers' Beliefs about Mathematics Teaching. Australian Journal of Teacher Education, 33(5), 5. http://doi.org/10.14221/ajte.2008v33n5.5

Çelik, D., Özmen, Z.M., Aydın, S., Güler, M., Birgin, O., Açıkyıldız, G., Gürsoy, K., Arabacı, D., Güneş, G., \& Gürbüz, R. (2018). A National Comparison of Pre-Service Elementary Mathematics Teachers' Beliefs about Aathematics: The case of Turkey. Education and Science, 43(193), 289-315 http://doi.org/10.15390/EB.2018.7133

Colaizzi, P. F. (1978). Psychological research as the phenomenologist views it. In R. Valle \& M. King (Eds.), Existential phenomenological alternatives in psychology (pp. 48-71). New York: Oxford University.

Coleman, L. J. (2014). The Cognitive Map of a Master Teacher Conducting Discussions with Gifted Students. Journal for the Education of the Gifted, 37(1), 40-55. https://doi.org/10.1177/0162353214521493

Creswell, J. W. (2013). Qualitative inquiry and research design: Choosing among five approaches (3rd ed.). Thousand Oaks, CA: Sage.

Dede, Y., \& Karakus, F. (2014). The Effect of Teacher Training Programs on PreService Mathematics Teachers' Beliefs towards Mathematics. Educational Sciences: Theory \& Practice, 14(2), 791-813. http://doi.org/10.12738/estp.2014.2.1787 
Demirsoy, N. H. (2008). Ilkogretim matematik ogretmenlerinin matematik hakkindaki inanclari, uygulamalari ve arasindaki iliski [Relationship between elementary mathematics teachers' beliefs about mathematics and their practices] (Unpublished master's thesis). Abant Izzet Baysal University, Bolu, Turkey.

Dixon, R. (2014). Cognitive Mapping Techniques: Implications for Research in Engineering and Technology Education. Journal of Technology Education, 25(2), 2-17.

Duatepe-Paksu, A. (2008). Comparing Teachers' Beliefs about Mathematics in terms of Their Branches and Gender. H. U. Journal of Education, 35, 87-97.

Ernest, P. (1989). The Knowledge, Beliefs, and Attitudes of the Mathematics Teacher: A Model. Journal of Education for Teaching, 15, 13-33. http://doi.org/10.1080/0260747890150102

Furinghetti, F., \& Pehkonen, E. (2002). Rethinking characterizations of belief. In G. Leder, E. Pehkonen, \& G. Toerner (Eds.), Beliefs: A hidden variable in mathematics education? (pp. 39- 58). Dordrecht: Kluwer Academic.

Glesne, C. (2011). Becoming qualitative researchers: An introduction. (4th ed.). Boston, MA: Pearson.

Grigutsch, S. (1998). On pupils' views of mathematics and self-concept: developments, structures and factors of influence (Research Report No. 195). In E. Pehkonen \& G. Torner (Eds.) The state-of-art in mathematics-related belief research. Results of the MAVI activities. (pp. 169-197). Helsinki: University of Helsinki.

Guba, E. G., \& Lincoln, Y. S. (1994). Competing paradigms in qualitative research. In N. K. Denzin \& Y. S. Lincoln (Eds.), Handbook of qualitative research (pp. 105-117). London: Sage.

Haser, C. (2006). Investigation of preservice and in-service teachers' beliefs related mathematics in Turkey and the perceived effect of middle school mathematics education program and the school contexts on these beliefs (Unpublished doctoral dissertation). Michigan State University, USA.

Haser, C., \& Dogan, O. (2012). Preservice Mathematics Teachers' Belief Systems. Journal of Education for Teaching, 38, 261-274. http://doi.org/10.1080/02607476.2012.668336

Haser, C., Kayan, R., \& Isiksal-Bostan, M. (2013). Preservice Mathematics Teachers' Beliefs about the Nature of Teaching and Learning Mathematics. Education and Science, 38(167), 179-195.

Herron, J. (2010). An Evolution of Mathematical Beliefs: A Case Study of Three Pre-k Teachers. Journal of Early Childhood Teacher Education, 31, 360-372. http://doi.org/10.1080/10901027.2010.523771 
Hewson, P. W., \& Hewson, M. G. A. B. (1989). Analysis and Use of a Task for Identifying Conceptions of Teaching Science. Journal of Education for Teaching, 15(3), 191- 209. http://doi.org/10.1080/0260747890150302

Irez, S. (2006). Are we prepared? An Assessment of Pre-Service Science Teacher Educators' Beliefs about Nature of Science. Science Education, 6(90), 1113-1143. http://doi.org/10.1002/sce.20156

Irez, S. (2007). Reflection-Oriented Qualitative Approach in Beliefs Research. Eurasia Journal of Mathematics, Science and Technology Education, 1(3), 17-27.

Isiksal, M., Kurt, G., Dogan, O., \& Cakiroglu, E. (2007). Epistemological Conceptions of Pre-Service Elementary Mathematics Teachers: Effects of University and Grade Level. Elementary Online, 6(2), 313-321.

Karakus, F. (2009). Matematik tarihinin matematik ogretiminde kullanilmasi: Karekok hesaplamada Babil Metodu [Using history of mathematics in mathematics teaching:

Maasepp, B., \& Bobis, J. (2015). Pre-Service Primary Teachers' Beliefs about Mathematics. Mathematics Teacher Education and Development, 16(2), 89-107.

Mellado, V. (1997). Preservice Teachers' Classroom Practice and their Conceptions of the Nature of Science. Science \& Education, 6, 331- 354.

Merriam, S. B. (2009). Qualitative Research: A guide to design and implementation. San Francisco, CA: John Wiley \& Sons.

Miles, M. B., \& Huberman, A. M. (1994). Qualitative data analysis: An expanded sourcebook (2nd ed.). Thousand Oaks: Sage.

MNE, (2013a). Elementary School Mathematics Curriculum (grades 5-8). Ministry of National Education, Ankara, Turkey.

MNE, (2013b). Mathematics Curriculum (grades 9-12). Ministry of National Education, Ankara, Turkey.

Munby, H. (1984). A Qualitative Approach to the Study of a Teacher's Beliefs. Journal of Research in Science Teaching, 21(1), 27-38. http://doi.org/10.1002/tea.3660210104

Northcott, N. (1996). Cognitive Mapping: An Approach to Qualitative Data Analysis. Journal of Research in Nursing November, 1(6), 456-463. http://doi.org/10.1177/174498719600100610.

Pajares, M. F. (1992). Teachers' Beliefs and Educational Research: Cleaning up a Messy Construct. Review of Educational Research, 62(3), 307-322. http://doi.org/10.3102/00346543062003307

Patton, M.Q. (2002). Qualitative research and evaluation methods. Thousand Oaks, CA: Sage. 
Pehkonen, E., \& Pietilä, A. (2003). On relationships between beliefs and knowledge in mathematics education. In Proceedings of the CERME 3: Third Conference of the European Society for Research in Mathematics Education, Balleria, Italy.

Philipp, R. A. (2007). Mathematics teachers' beliefs and affect. In F. K. Lester, Jr. (Ed.) Second handbook of research on mathematics teaching and learning (pp. 257-315). Charlotte, NC: Information Age.

Raymond, A. M. (1997). Inconsistency between a Beginning Elementary School Teacher's Mathematics Beliefs and Teaching Practice. Journal for Research in Mathematics Education, 28, 550-576. http://doi.org/10.2307/749691

Schoenfeld, A. H. (1992). Learning to think mathematically: problem solving, metacognition, and sense making in mathematics. In D. A. Grouws (Ed.). Handbook of research on mathematics learning and teaching (pp. 334-370). New York: Macmillan.

Schunk, D. H. (1991). Self-Efficacy and Academic Motivation. Educational psychologist, 26(3-4), 207-231. http://doi.org/0.1080/00461520.1991.9653133

Spangler, D. A. (1992). Assessing Students' Beliefs about Mathematics. The Mathematics Educator, 3(1), 19-25.

Steinberg, H. (1998). Elements of Epistemological Knowledge for Mathematics Teacher. Journal of Mathematics Teacher Education, 1, 157-189. http://doi.org/10.1023/A:1009984621792

Thompson, A. G. (1991). The development of teachers' conceptions of mathematics teaching. In R. G. Underhill (Eds.), Proceedings of the thirteenth annual meeting of the north American chapter of the international group for the psychology of mathematics education. Vol 2. (pp. 8-14).

Thompson, A. G. (1992). Teachers' beliefs and conceptions: A synthesis of the research. In A. D. Grouws (Ed.), Handbook of research on mathematics learning and teaching (pp. 127-146). New York: Macmillan.

Tillema, E. (2005). Chinese Algebra: Using Historical Problems to Think about Current Curricula. Mathematics Teacher, 99(4), 238-245.

Toluk-Ucar, Z., \& Demirsoy, N. H. (2010). Eski-yeni Ikilemi: Matematik Öğretmenlerinin Matematiksel Inançlari ve Uygulamalari [Tension between old and new: Mathematics teachers' beliefs and practices]. H. U. Journal of Education, 39, 321332.

Unlu, M., \& Aktas, G. S. (2013). Beliefs' of Pre-Service Elementary Mathematics Teachers' and Mathematics Department Students' about Mathematics. Procedia-Social and Behavioral Sciences, 93, 742-746. http://doi.org/10.1016/j.sbspro.2013.09.273

White, B. C. (2000). Pre-Service Teachers' Epistemology Viewed through Perspectives on Problematic Classroom Situations. Journal of Education for Teaching, 26 (3), 279305. http://doi.org/10.1080/713676891 
Wilkins, J., \& Brand, B. (2004). Change in Preservice Teachers' Beliefs: An evaluation of a Mathematics Methods Course. School Science and Mathematics, 104(5), 226-232. http://doi.org/10.1111/j.1949-8594.2004.tb18245.x

Yang, X., \& Leung, F. K. S. (2015). The Relationships among Pre-Service Mathematics Teachers' Beliefs about Mathematics, Mathematics Teaching, and Use of Technology in China. Eurasia Journal of Mathematics, Science \& Technology Education, 11(6), 13631378. http://doi.org/10.12973/eurasia.2015.1393a 